Citation: Morschheuser B., Henzi C. \& Alt R. (2015). Increasing Intranet Usage Through Gamification - Insights from an Experiment in the Banking Industry. In proceedings of the 48th Annual Hawaii International Conference on System Sciences (HICSS), Hawaii, USA, January 5-8, 2015.

Copyright: (C) 2015 IEEE. Personal use of this material is permitted. Permission from IEEE must be obtained for all other uses, in any current or future media, including reprinting/republishing this material for advertising or promotional purposes, creating new collective works, for resale or redistribution to servers or lists, or reuse of any copyrighted component of this work in other works.

\title{
Increasing intranet usage through gamification - insights from an experiment in the banking industry
}

\author{
Benedikt Morschheuser \\ University of Leipzig \\ benedikt.morschheuser@uni- \\ leipzig.de
}

\author{
Christian Henzi \\ University of St. Gallen \\ christian.henzi@student.unisg.ch
}

\author{
Rainer Alt \\ University of Leipzig \\ rainer.alt@uni-leipzig.de
}

\begin{abstract}
This paper applies gamification to leverage the use of information for information-intensive business tasks in the context of corporate intranets. It presents the results of an online experiment, which was conducted in the banking industry with 68 advisors from different institutes using a prototype of a corporate intranet. They indicate that adding gamification elements, such as ranking lists and points, positively influences the quantitative (time spent, articles read) and qualitative (time per article, percentage of correct answers) usage of the intranet for knowledge acquisition.
\end{abstract}

\section{Introduction}

Customers expect financial advisors to have accurate and up-to-date knowledge about the developments in the banking industry and the financial markets [29]. This knowledge builds trust and is one of the factors that influences the experienced service quality [29]. As the service quality is an important factor for customer satisfaction [38], it is key for banking customers that the financial advisors have adequate up-to-date knowledge about the current developments in the banking industry and the financial markets.

Clients define the specialized knowledge of advisors as a key factor for the service quality [22]. This is partly due to the fact that they increasingly inform themselves. Information-intensive customer service processes, such as financial advises, require a high motivation to learn about new products, market developments and the like and a desire to continuously improve themselves [45].

One approach for organizations to support the continuous knowledge acquisition and learning of employees are corporate intranet systems [19] with formal (e.g. e-learning [43]) and informal (e.g. news, communities and market information) learning resources. Intranets are in particular used to inform and train employees [23, 33]. In large financial institutions research and support teams constantly gather useful information and make it available on the corporate intranet. Banks are known as heavy users of intranets since the knowledge of the entire organization and its employees [36] is a critical competitive factor.

Thus the question will be raised how the usage of a corporate intranet may be improved. This is especially interesting for knowledge that needs to be upto-date. For example, information about the performance of the various financial markets has to be looked up as part of the preparation process for an individual advisory meeting.

Recently there has been a growing interest in 'the use of game design elements in non-game contexts' [6], also known as gamification, to increase the usage of information systems in several business contexts, including employee networks [9, 42], ERP systems [16], innovation [20] and education [1,25].

In the context of intranets of financial institutions, gamification may motivate advisors to use such tools. This paper aims to contribute to the empirical evidence in the field by designing, implementing and evaluating a gamified intranet system.

\section{Background}

The term "Gamification" describes the use of video game elements in non-game systems and services to improve user experience and user engagement $[6,18]$. Numerous empirical studies have shown that gamification can have positive effects in a wide range of contexts [15].

The use of gamification to increase motivation and engagement represents an important development in the context of learning [15, 21,31]. Already in the 1980s, Malone and Lepper analyzed the positive impact of game elements in context of learning [27]. Several recent studies have shown that gamification approaches can improve learning environments for students $[3-5,7,10,13,14,30,40]$ and training ap- 
plications for clients $[8,26]$. The potential of gamification for learning and gaining knowledge in the business context has only received little attention so far.

Intranets have been established in large organizations as a central environment to create and manage knowledge $[39,41]$. Due to the wide range of possible roles and functions of corporate intranets, there exist several different definitions of the term itself [19]. Based on Jacko et al. (2002) [19] and Huber (1991) [17] intranets are information systems that help to acquire, memory, distribute and interpret information and knowledge in organizations. Especially in large, distributed enterprises the application of intranets is beneficial [19]. By serving as a centralized dynamic knowledge repository, intranets provide employees a corporate learning environment.

Looking at the results from other studies focusing on the benefits of gamification for learning environments, we assume that corporate intranets could also profit from gamification approaches. Therefore, the target of this research is to examine, whether gamification may improve the motivation to use information in intranets in a quantitative and qualitative manner. For this purpose an experiment was conducted in a use case from the banking industry.

\section{Gamifying a corporate intranet}

At the heart of this research, a prototype was developed, allowing us to analyze the impact of gamification on the quantitative (general usages) and qualitative (knowledge acquisition) usage of intranets in an experiment.

For designing the prototype, the intranet of a big Swiss bank was taken as a model and marked with a fictitious bank brand. Relevant news articles based on real events were created as content for the intranet.

An innovation compared to conventional intranet solutions was the implementation of a "check your knowledge" quiz function. After reading and closing an article, users were redirected to a page where they could answer a knowledge question about it and test their understanding of this article. Four possible answers were displayed and a "close button" to ignore the quiz was available. Rothkopf $[34,35]$ has shown that answering questions after reading a text can cause learning effects (thinking about the content) and improve retention. This approach, also known as "mathemagenic" [12], may increase the attention of learners and promote their understanding of texts as learning materials. Therefore, the addition of voluntary control questions seems to be a useful extension for learning materials in intranets.

On this basis, two versions of this prototype were created: A gamified version (treatment group) with rewarding gamification elements (see Figure 1) and a version without rewards (control group). Prior to designing a gamified application it is important to understand who the player will be, what their intrinsic motivation is and how the underlying business processes are designed. Based on that, game mechanisms, such as collecting, gifting and gaining status and elements like points, badges and leaderboards can be selected and applied [24, 44]. Therefore, the player-centered design model is a widely used approach to successfully design gamified applications $[24,32]$. In a software design process, based on this concept, gamification elements matching the situation and the users were selected. First, the user group was analyzed by conducting interviews with experts. A private banking financial advisor being part of the sales force used to be ranked and has very specific

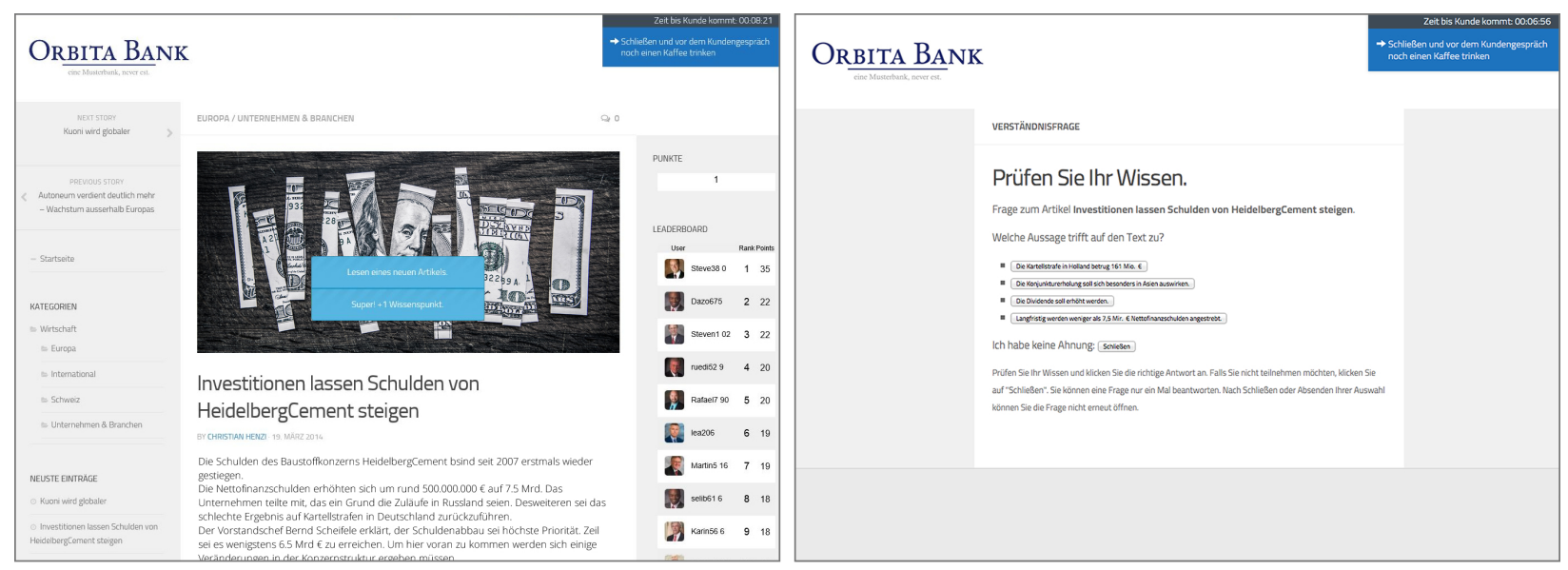

Figure 1. Gamified version of the intranet prototype and "check your knowledge" quiz 
goals to achieve. Furthermore, it may be stated that the work culture is formal and highly competitive. It may be concluded that a player aims to play to gain fortune and status, which matches the definition of an "Achiever" player type [2]. Based on this finding and in consideration of best practice results (see e.g. Zichermann, G. and Cunningham [44] and Radoff [32]) points and rankings were chosen as corresponding game elements. This is supported by Mekler et al. [28], which find that points and leaderboards are two of the most commonly used [15] gamification elements with a verifiable positive effect on user behavior.

Therefore, the group with the gamified version (treatment group) experienced two instant rewarding gamification elements: points and a ranking.

Opening an article was rewarded ( +1 point), as this action was desired. Answering a questionnaire with a correct answer was rewarded with several points ( +4 points). The participants were not informed about the points which could be gained to guarantee the same starting point like the control group with the non gamified version. Immediately after receiving the points the anytime displayed ranking position was adjusted and the new rank visible. These two mechanics were combined to create an aesthetics of challenge and competition [37]. This was due to the fact that those aesthetics also could be found in their daily life and would support players who are achievers [32, 44].

An exit button allowed all participants to stop the experiment at any possible time to guarantee the voluntariness during the whole process.

\section{Experiment}

An online experiment was conducted based on a between subject design to analyze, whether the moti- vation to read and understand information as well as learning content in a corporate intranet for banking advisors could be improved by adding gamification elements.

\subsection{Setting and design}

In order to keep the experiment as real as possible, the story of the experiment was defined as a simulated preparation process for a possible client advisory meeting. The participants were informed about the client (age, assets under management, investment focus) and the remaining time frame (10 minutes) until the arrival of the customer. Subsequently, the participants logged into a simulated intranet, where by random they were split into the treatment and control group (see Figure 2).

The experiment began with the login to the simulated intranet. Several articles were presented and the participants were able to choose which ones they wanted to read. After reading each article, a quiz with four possible answers popped up and the reader was able to either answer or skip the quiz. The difference between the control group and the treatment group was that in case of opening an article and answering the quiz correctly, the treatment group earned points. Furthermore, a ranking was visible and the points earned defined the rank on the leaderboard. The control group experienced the same process but without the gaming elements (points and ranking).

A timer, which informed about how much time was remaining, completed the setting. At each given point, the participant could end the experiment by clicking an "I don't want to read further and will now take a coffee break" button. Otherwise the experiment would close itself after ten minutes.

Subsequently, a questionnaire elevated further information about the participants (sex, age, years of

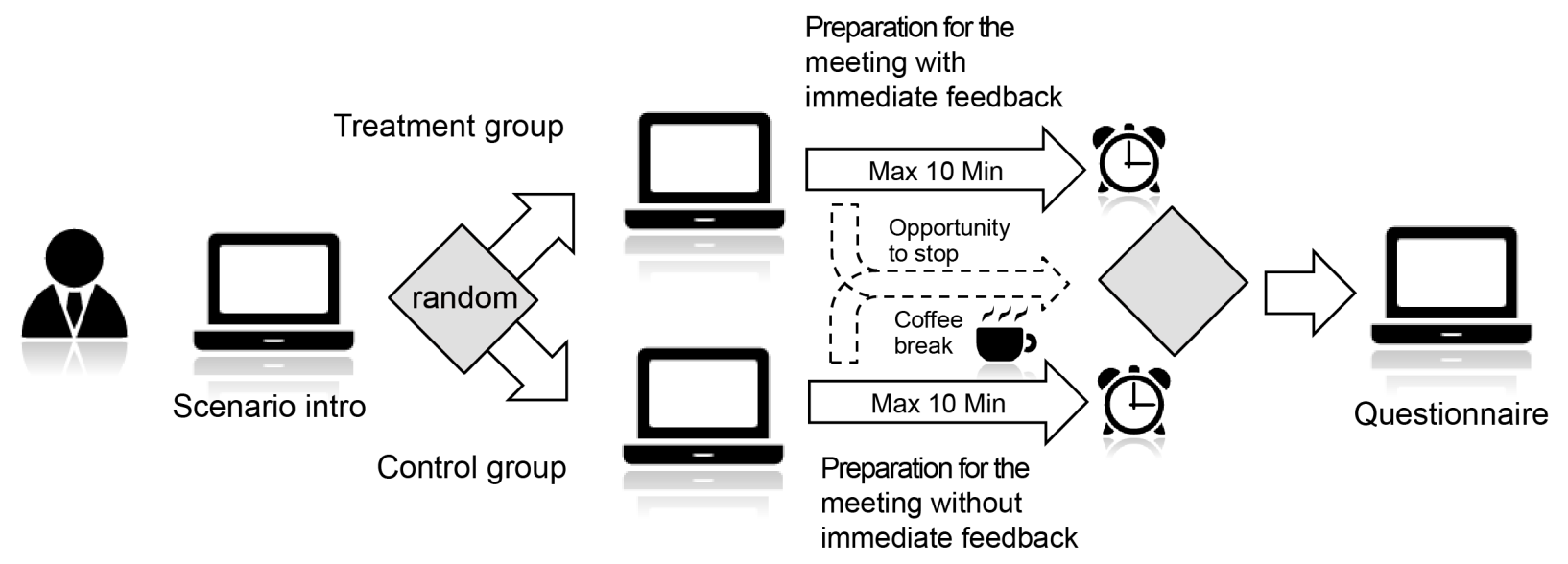

Figure 2. Setting of the experiment 
service, video gaming per week) and about their client segment (assets under management, number of customer and preparation time), which was used as control variables.

\subsection{Hypotheses}

Several studies have shown that gamification could have a positive effect on the usage of information systems $[9,28,42]$ and learning environments [3-5, $7,10,13,14,30,40]$. Therefore we posit that adding gamification elements, like points and leaderboards, to an intranet will increase the general usage as well as knowledge acquisition of the users. To research this possible impact the experiment attempts to answer the following hypotheses:

H1: The usage of gamification elements has a positive effect on the total time spent on the intranet and the numbers of articles read.

H2: The usage of gamification elements has a positive effect on the time spent per article.

H3: The usage of gamification elements has a positive effect on the number of control questions answered and the number of correctly answered questions.

H4: The usage of gamification elements has a positive effect on the percentage of the questions answered correctly.

The usage differences between the gamified and non-gamified version were measured by six endogenous variables (Table 1). The time spent on the intranet (V1), the number of articles read (V2), the number of voluntarily answered control questions (V4) and the number of correctly answered control questions (V5) are indicators for the quantitative use of the analyzed intranet. However, purely quantitaive measures are not enough to capture if the content was also understood by the user. In this sense, to measure the quality of the usage, the time spent per article (V3) and the percentage of questions answered correctly (V6) were computed.

Table 1. Variables

\begin{tabular}{|l|l|}
\hline V1 & Total time spent on the intranet. \\
\hline V2 & Numbers of articles read. \\
\hline V3 & Time spent per article. \\
\hline V4 & Number of control questions answered. \\
\hline V5 & Number of correctly answered questions. \\
\hline V6 & Percentage of the questions answered correctly. \\
\hline
\end{tabular}

\subsection{Execution}

The experiment was available for 30 days online and was protected by a password-login to secure the qualification of the participants. To ensure the diversification in the aspects of geography, age and years of service, banks as well as educational institutions for the banking industry were contacted. During one month, participation was possible and data was gathered.

\section{Results}

During the one-month period, financial advisors from different banks (Switzerland and Germany) participated in the experiment. A total set of 68 valid data records built the foundation for the analysis.

\subsection{Sample}

Participants ${ }^{1}$ from different banks (size and client focus, but all within the private banking division) in different geographic locations (Switzerland and Germany) contributed to the experiment. At the time of the experiment, they all were working in the banking industry, had an education in banking and at least one year of service experience. Furthermore, the participants were familiar with an intranet solution and the usage of this system in the preparation process.

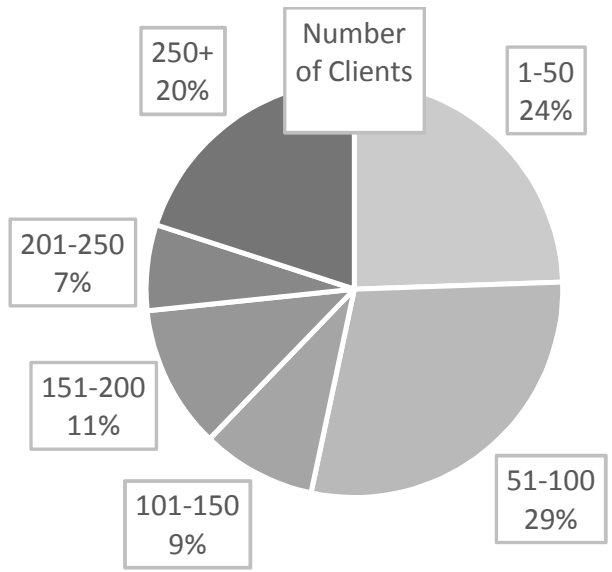

Figure 3. Number of clients advised per advisor

The age range spans from 17 to 55 years and the range of years of service experience from 1 to 30 . Besides the variation in personal details, also different segments of customers were considered (see Figure 3 ). The number of customers served per advisor reaches from $<50$ up to over 250 . The volume of assets under management goes from $>50$ '000 CHF to more than 250'000 CHF per client. The structure of

\footnotetext{
${ }^{1}$ Additional information was only provided by 45 participants
} 
the number of clients served and segment of served customer per assets under management (AuM) is shown in Figure 4.

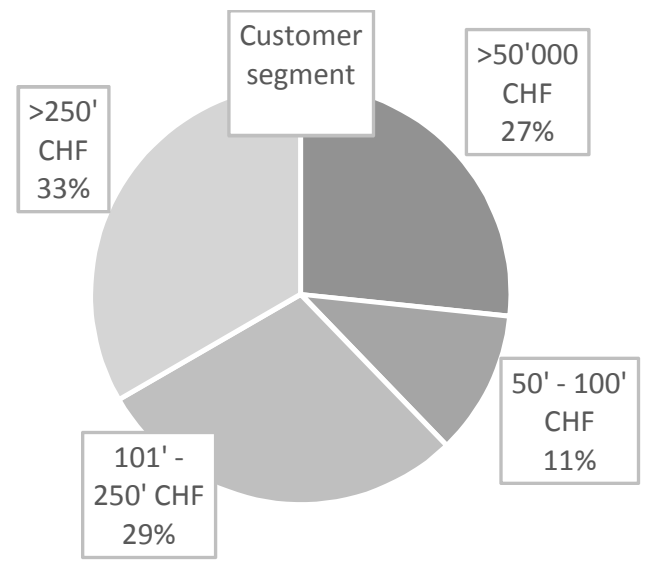

Figure 4. AuM per customer

\subsection{Control variables}

The separation into gamification $(\mathrm{N}=36)$ and nongamification $(\mathrm{N}=32)$ groups was random. To ensure that no correlation or statistical significant factor influenced either of each group, correlation between the separation and the variables was executed. For age, years of service, number of customers, customer segment and gaming per week no correlation was found. The correlation between gamification and gender has phi-coefficient of less than 0.3 and is therefore trivial [11]. A significance level of $\alpha=0.05$ was used.

Therefore, it can be concluded that the automatic randomization of the participants into the treatment group and control group was homogenously distributed.

\subsection{Analysis of the endogenous variables}

Prior to testing the significances of the single factors, a Kolmogorov-Simirnov and a Shapiro-Wilk test were conducted to test for normal distribution. All factors are not normally distributed for $\alpha=0.05$. Hence, Mann-Whitney tests were conducted to compare the means between the two independent samples of gamification and non-gamification.

\subsection{Hypotheses testing}

To put the results into perspective, the single hypothesis are reviewed and put into the context.

H1: The results show that the adding of gamification elements increased the overall time spent on the intranet from a mean of 2.59 (156 seconds) minutes to 5.30 (318 seconds) minutes. The application of a Mann-Whitney test verified the assumption as a highly significant difference between the two independent groups (Table 2). The number of articles read was significantly improved by two and a half times from 1.56 to 3.91 in the gamified version. These results indicate that the pure quantity of time can significant-

Table 2. Means and standard deviation

\begin{tabular}{|l|l|l|l|l|}
\hline \multirow{2}{*}{ Variable } & \multicolumn{2}{|l|}{ Without gamification } & With gamification \\
\cline { 2 - 5 } & Mean & $\begin{array}{l}\text { Standard } \\
\text { deviation }\end{array}$ & Mean & $\begin{array}{l}\text { Standard } \\
\text { deviation }\end{array}$ \\
\hline $\begin{array}{l}\text { Total time spent on } \\
\text { the intranet (minutes) }\end{array}$ & 2.5938 & 2.29919 & $5.3056^{* * *}$ & 3.85728 \\
\hline $\begin{array}{l}\text { Number of articles } \\
\text { read }\end{array}$ & 1.5625 & 2.61336 & $3.9167^{* *}$ & 3.51177 \\
\hline $\begin{array}{l}\text { Time spent per article } \\
\text { (minutes) }\end{array}$ & 0.5688 & 0.73047 & $0.9753^{*}$ & 0.68754 \\
\hline $\begin{array}{l}\text { Number of control } \\
\text { questions answered }\end{array}$ & 0.8438 & 1.85106 & $3.0556^{* * *}$ & 3.67963 \\
\hline $\begin{array}{l}\text { Number of correctly } \\
\text { answered questions }\end{array}$ & 0.2813 & 0.72887 & $1.4167^{* * *}$ & 1.48083 \\
\hline $\begin{array}{l}\text { Percentage of correct } \\
\text { answers (in \%) }\end{array}$ & 8.59 & 0.25879 & $26.69^{* *}$ & 0.33184 \\
\hline
\end{tabular}

* Significant at 0.05 level (two-tailed test);

** Significant at 0.01 level (two-tailed test);

*** Significant at 0.001 level (two-tailed test); 
ly be improved and the motivation to stay on the intranet and read more articles about customer related topics was successfully achieved.

$\mathrm{H} 2$ : Whether the time is spent in a meaningful way was tested by the time spent per article. The adding shows that the mean was almost doubled from 0.57 (34 seconds) minutes to 0.98 (59 seconds). This indicates that gamification does not only support quantitative goals but also matches the requirements for a qualitative improvement.

H3: The number of questions answered increased significantly by more than three and a half times from 0.84 to 3.06 . This result is especially interesting as the participant was able to choose to answer the question or not. It indicates that even though the participants read more articles, they read those more carefully so that they felt secure enough to answer the questions instead of skipping them. Besides the higher number of questions answered, these answers were also more often correct, shown by the average of the correct answers given. With gamification, the answers given shot up by five, from an average of 0.28 to 1.41 .

H4: To ensure that not only the quantity but also the quality of the answers improved, the percentage of the questions answered correctly was tested (number of correct answers given / answers given). There was an improvement by a factor of three. The average rose from $8.59 \%$ up to $25.88 \%$. This is especially interesting as the answering was voluntary and only correct answers were honored with points. Furthermore, the number of given answers increased as well, so this result is even more impressive. This indicates that the effort invested in the preparation process was truly increased.

All hypothesizes could be statistically confirmed by the application of Mann-Whitney tests (Table 2), which indicates that the use of gamification elements in an intranet for advisors could increase the motivation to use such tools as part of a client meeting preparations and can support the individual learning process.

\section{Discussion and Conclusion}

This study shows that the usage of gamification elements can intensify the usage of a corporate intranet as information source for market information for financial advisors. The time spent on the platform and per article was increased significantly. Furthermore, voluntary "check your knowledge" questions were answered more often and the percentage of correct answers increased. This leads to the result, that not only more information was gathered (articles read), but also that those articles were read more carefully (number of correct answers and time spent per article).

In case of companies with a wide network of branch office using intranets to distribute information to their advisors, like financial institutions, but also travel agencies or insurers, gamification seems to be an appropriate approach to support this information distribution. Considering the finding that not only the quantitative usage, but also the percentage of correct answers increased, it may be concluded that gamification can also promote learning.

In the financial industry, in which the knowledge of the advisors has a potential influence on the service quality [29] and therefore on the customer satisfaction [38], our approach could have a real positive business impact. With the availability of games on mobile devices future advisors are already gaming on a regular basis. This familiarity reduces the constraints towards new solutions and could make the usage of gamification even more effective.

Regarding the limitations of this work it is to be noted that the effects were only collected during a short timeframe with a small sample of 68 participants. Further long-term studies with praxis partners are planned. In addition, the link from preparation to service quality is assumed based on a customer survey. The potential correlation between continuous learning and knowledge acquisition about news and market trends and the assumed impact on the advisory service and customer satisfaction should be examined in more detail to estimate the business impact. The gamification elements used in this study are common and proofed but also very elementary. Mekler et al. [28] and others [15] have shown that they can be used to analyze short-term gamification effects. Nevertheless further gamification elements and design adaptions could be needed and should be studied to achieve possible long-term effects. Furthermore, future studies are needed to assess the potential and importance for companies but also possible barriers.

Nevertheless, this study provides a first important contribution to the successful use of gamification approaches to improve the delivery of information with corporate intranets and promote a more efficient learning and knowledge acquisition. 


\section{References}

[1] Banfield, J., and Wilkerson, B., "Increasing Student Intrinsic Motivation and Self-Efficacy through Gamification Pedagogy", In Proceedings of the Clute Institute International Academic Conference, Orlando, Florida, 2014, pp. 50-58.

[2] Bartle, R., "Hearts, Clubs, Diamonds, Spades: Players Who Suit Muds", Journal of MUD Research, 1(1), 1996, pp. 19.

[3] Charles, T., Bustard, D., and Black, M., "Experiences of Promoting Student Engagement through Game-Enhanced Learning", In Ma, M., Oikonomou, A., and Jain, L.C. (Eds.): Serious Games and Edutainment Applications, Springer, London, 2011, pp. 425-445.

[4] Cheong, C., Cheong, F., and Filippou, J., "Quick Quiz: A Gamified Approach for Enhancing Learning", In Proceedings of Pacific Asia Conference on Information Systems, Jeju Island, Korea., 2013, pp. 1-14.

[5] Denny, P., "The Effect of Virtual Achievements on Student Engagement", In Proceedings of CHI 2013: Changing Perspectives, Paris, France, 2013, pp. 763-772.

[6] Deterding, S., Dixon, D., Khaled, R., and Nacke, L., "From Game Design Elements to Gamefulness: Defining 'Gamification'", In Proceedings of the 15th International Academic MindTrek Conference: Envisioning Future Media Environments, Tampere, Finland, 2011, pp. 9-15.

[7] Domínguez, A., Saenz-De-Navarrete, J., De-Marcos, L., Fernández-Sanz, L., Pagés, C., and Martínez-Herráiz, J.J., "Gamifying Learning Experiences: Practical Implications and Outcomes", Computers \& Education, 63(2013, pp. 380-392.

[8] Dong, T., Dontcheva, M., Joseph, D., Karahalios, K., Newman, M.W., and Ackerman, M.S., "Discovery-Based Games for Learning Software", In Proceedings of the annual conference on Human Factors in Computing Systems, Austin, Texas, 2012, pp. 2083-2086.

[9] Farzan, R., Dimicco, J.M., Millen, D.R., Brownholtz, B., Geyer, W., and Dugan, C., "When the Experiment Is Over: Deploying an Incentive System to All the Users", In Proceedings of the Symposium on Persuasive Technology, 2008

[10] Fitz-Walter, Z., Tjondronegoro, D., and Wyeth, P., "Orientation Passport: Using Gamification to Engage University Students", In Proceedings of the 23rd Australian Computer-Human Interaction Conference, Canberra, Australia, 2011, pp. 122-125.

[11] Fleiss, J., Levin, B., and Paik, M., Statistical Methods for Rates and Proportions, John Wiley \& Sons, New York, 2003.
[12] Frase, L.T., "Boundary Conditions for Mathemagenic Behaviors", Review of Educational Research, 40(3), 1970, pp. 337-347.

[13] Hakulinen, L., Auvinen, T., and Korhonen, A., "Empirical Study on the Effect of Achievement Badges in Trakla2 Online Learning Environment", In Proceedings of Learning and Teaching in Computing and Engineering (LaTiCE) conference, Macau, 2013, pp. 47-54.

[14] Halan, S., Rossen, B., Cendan, J., and Lok, B., "High Score!-Motivation Strategies for User Participation in Virtual Human Development", In Proceedings of the international conference on Intelligent Virtual Agents, Berlin/Heidelberg, 2010, pp. 482-488.

[15] Hamari, J., Koivisto, J., and Sarsa, H., "Does Gamification Work? - a Literature Review of Empirical Studies on Gamification", In Proceedings of the 47th Hawaii International Conference on System Sciences, Hawaii, USA, 2014, pp. 3025-3034.

[16] Herzig, P., Strahringer, S., and Ameling, M., "Gamification of Erp Systems - Exploring Gamification Effects on User Acceptance Constructs", In Multikonferenz Wirtschaftsinformatik MKWI'12, Braunschweig, Germany, 2012, pp. 793-804.

[17] Huber, G.P., "Organizational Learning: The Contributing Processes and the Literatures", Organizational Science, 2(1), 1991, pp. 89-115.

[18] Huotari, K., and Hamari, J., "Defining Gamification a Service Marketing Perspective", In Proceeding of the 16th International Academic MindTrek Conference, Tampere, Finland, 2012, pp. 17-22.

[19] Jacko, J.A., Salvendy, G., and Sainfort, F., "Intranets and Organizational Learning: A Research and Development Agenda", International Journal of Human-Computer Interaction, 14(1), 2002, pp. 93-130.

[20] Jung, J., Schneider, C., and Valcich, J., "Enhancing the Motivational Affordance of Information Systems: The Effects of Real-Time Performance Feedback and Goal Setting in Group Collaboration Environments", Management Science, 56(4), 2010, pp. 724-742.

[21] Kapp, K., The Gamification of Learning and Instruction: Game-Based Methods and Strategies for Training and Education, Pfeiffer, San Francisco, 2012.

[22] Khan, I., Blumer, A., and Schäfer, D., Retail Banking 2020, Ernst \& Young and University of St. Gallen, 2012.

[23] Krautwurst, O., "Intranet-Einsatz Im Bankbetrieblichen Personalmanagement", In Riekeber, M., and Stenke, K. (Eds.): Banking 2000, Gabler Verlag, Wiesbaden, 2000, pp. 309-325. 
[24] Kumar, J., "Gamification at Work: Designing Engaging Business Software", In Aaron, M. (Ed.): Design, User Experience, and Usability. Health, Learning, Playing, Cultural, and Cross-Cultural User Experience, Springer, Berlin, 2013, pp. 528-537.

[25] Lee, J.J., and Hammer, J., "Gamification in Education: What, How, Why Bother?", Academic Exchange Quarterly, 15(2), 2011, pp. 1-5.

[26] Li, W., Grossman, T., and Fitzmaurice, G., "Gamicad: A Gamified Tutorial System for First Time Autocad Users", In Proceedings of the 25th annual ACM symposium on User interface software and technology, Cambridge, Massachusetts, 2012, pp. 103-112.

[27] Malone, T.W., and Lepper, M.R., "Making Learning Fun: A Taxonomy of Intrinsic Motivations for Learning", In Snow, R.E., and Farr, M.J. (Eds.): Aptitude, Learning, and Instruction, 3 edn., Lawrence Erlbaum, Hillsdale, 1987, pp. 223-253.

[28] Mekler, E.D., Brühlmann, F., Opwis, K., and Tuch, A.N., "Do Points, Levels and Leaderboards Harm Intrinsic Motivation?: An Empirical Analysis of Common Gamification Elements", In Proceedings of the First International Conference on Gameful Design, Research, and Applications, Waterloo, Canada, 2013, pp. 66-73.

[29] Mogicato, R., Schawe, G., Nussbaumer, P., Stehli, E., and Eberhard, M., "Beraterqualität in Banken. Was Der Kunde Erwartet. Was Der Kunde Erlebt", 2009,

[30] Morschheuser, B.S., Rivera-Pelayo, V., Mazarakis, A., and Zacharias, V., "Interaction and Reflection with Quantified Self and Gamification: An Experimental Study", Journal of Literacy and Technology, 15(2), 2014, pp. 136-156.

[31] Muntean, C.I., "Raising Engagement in E-Learning through Gamification", In Proceedings of the 6th International Conference on Virtual Learning ICVL, Bukarest, 2011, pp. 323-329.

[32] Radoff, J., Game On: Energize Your Business with Social Media Games, Wiley Publishing, Inc., Indianapolis, Indiana, 2011.

[33] Reich, T., "Smartnet Als Kernstuck Des Intranets Der Credit Suisse", In Bach, V., Österle, H., and Vogler, P. (Eds.): Business Knowledge Management in Der Praxis, Springer, Berlin, 2000, pp. 193-219.

[34] Rothkopf, E.Z., "Learning from Written Instructive Materials: An Exploration of the Control of Inspection Behavior by Test-Like Events", American Educational Research Journal, 3(4), 1966, pp. 241-249.

[35] Rothkopf, E.Z., "Adjunct Aids and the Control of Mathemagenic Activities During Purposeful Reading", In Otto, W., and White, S. (Eds.): Reading Expository Material, Academic Press, New York, 1982, pp. 109-138.
[36] Schatte, N., Analyse Ausgewählter Ansätze Zur Wissensgenerierung in Kreditinstituten Auf Dem Weg Zu Einer Lernenden Organisation, Shaker, Aachen, 2008.

[37] Schell, J., The Art of Game Design: A Book of Lenses, Morgan Kaufmann Publishers, Burlington, 2008.

[38] Schlich, B., "The Customer Takes Control: Global Consumer Banking Survey 2012", 2012,

[39] Scott, J.E., "Organizational Knowledge and the Intranet", Decision Support Systems, 23(1), 1998, pp. 3-17.

[40] Smith, A.L., and Baker, L., "Getting a Clue: Creating Student Detectives and Dragon Slayers in Your Library", Reference Services Review, 39(4), 2011, pp. 628-642.

[41] Stenmark, D., "Information Vs. Knowledge: The Role of Intranets in Knowledge Management", In Proceedings of the 35th Annual Hawaii International Conference on System Sciences HICSS, Hawaii, USA, 2002, pp. 928-937.

[42] Thom, J., Millen, D.R., Dimicco, J., and Street, R., "Removing Gamification from an Enterprise Sns", In Proceedings of the ACM 2012 conference on Computer Supported Cooperative Work CSCW '12, New York, 2012, pp. 1067-1070.

[43] Welsh, E.T., Wanberg, C.R., Brown, K., and M, S., "E-Learning: Emerging Uses, Empirical Results and Future Directions", International Journal of Training and Development, 7(4), 2003, pp. 245-258.

[44] Zichermann, G., and Cunningham, C., Gamification by Design: Implementing Game Mechanics in Web and Mobile Apps, O'Reilly Media, Inc., 2011.

[45] Ziegler, S., Sigg, A., Fehr, R., Zaugg, J., Brunner, H., and Hofmann, R., Die Neupositionierung Des Wealth Management in Der Schweiz Entwicklungen Und Ihre Auswirkungen Auf Die Soll-Kompetenzen in Der Kundenberatung, Zhaw: School of Management and Law, Winterthur, 2014. 